\title{
humanidades
}

Revista humanidades

Enero-junio, 2016 • Volumen 6, número 1 • ISSN 2215-3934 • pp. 1-32

\section{La moral, los roles, los estereotipos femeninos y la violencia simbólica}

DOI: http://dx.doi.org/10.15517/h.v6i1.24964

\section{Nazira Álvarez Espinoza}

Profesora en la Escuela de Filología, Lingüística y Literatura de la Universidad de Costa Rica.

Correo electrónico: calipso36@yahoo.com

Todos los derechos reservados. Universidad de Costa Rica. Esta revista se encuentra licenciada con Creative Commons Reconocimiento-NoComercial-SinObraDerivada 3.0 Costa Rica.

Correo electrónico: humanidades@ucr.ac.cr / Sitio web: http://revistas.ucr.ac.cr/index.php/humanidades 


\title{
La moral, los roles, los estereotipos femeninos y la violencia simbólica
}

\section{Resumen}

El análisis realiza un breve recorrido por las principales teorías de evolución socio-cognitiva y su relación con la creación de las normas, instituciones, la cultura y la moral. La relación entre los roles sociales y la moral crean los estereotipos femeninos de género a través de los cuales se sanciona y se autorregula la conducta femenina transgresora de los valores establecidos por la colectividad.

Palabras clave: Violencia, moral, estereotipos, roles de género, violencia simbólica.

\section{Morality, Role, Gender Stereotypes and Symbolic Power}

\begin{abstract}
The analysis takes a brief tour of the major socio-cognitive theories of evolution and its relationship to the creation of rules, institutions, culture and morality. The relationship between social roles and moral creates female gender stereotypes through which there is self-regulation and punishment towards the offending female behaviors towards the values established by the community.
\end{abstract}

Keywords: Violence, morality, gender stereotypes, gender roles, symbolic power. 
Este trabajo aborda las principales teorías de la evolución socio-cognitiva y su relación con la creación de las normas, instituciones, la cultura y la moral. Por medio de diferentes estudios y autores, se analiza cómo los roles femeninos que han sido impuestos por la sociedad crean estereotipos que se refuerzan por el uso de sanciones y autorregulaciones sobre el colectivo femenino. A la vez, se realiza un estudio sobre las consecuencias de las sanciones sobre las mujeres y la presencia de una violencia simbólica que se ejerce sobre la mujer con el fin de controlar y modificar su comportamiento dentro de la sociedad.

En los orígenes de las sociedades humanas, las jerarquías sociales surgieron como una necesidad comunitaria para la cooperación y la colaboración. La moral nace como producto de un proceso de control y auto-regulación para la colectividad. Los posibles orígenes de la dinámica de la evolución donde se crearon nuevas y diversas funciones del pensamiento humano y las estructuras jerárquicas en los procesos evolutivos forman parte de la tesis de Tomasello (2014) sobre la emergencia de la intencionalidad compartida, la cual propició la restructuración, la transformación y la socialización de los procesos de la individualidad y el pensamiento individual. En relación con la socialización y el pensamiento existen diferentes teorías sobre su evolución.

Desde la perspectiva de Tomasello (2014) la interrelación de la socialización y la cognición son importantes para la colaboración y la comunicación cooperativa. Los estatutos sociales y la representación de los esquemas de comportamiento para los integrantes del grupo comparten rasgos de dominación y sumisión. La precedencia del género sobre otras categorías como la edad o el estatus social se convirtió en una 
caracterización persistente de la legitimación del discurso del poder masculino en las diferentes épocas y contextos socio-culturales.

En el libro A Natural History of Human Thinking Tomasello (2014) la tesis fundamental del autor es la propuesta de que la evolución del pensamiento y la cognición humana surgieron entrelazadas en la matriz sociocultural. En los orígenes la coordinación y la cooperación, unidas a la aparición temprana de un amplio repertorio de habilidades cognitivas y motivacionales, facilitó la aparición de la intencionalidad compartida. La capacidad de reconocer la existencia de identidades -en los otros agentes-, las características personales, las concepciones, las emociones, los objetivos, las percepciones del mundo y la transmisión de las prácticas culturales convierte a la especie humana en pro-social (Tomasello, 2008). Lo anterior hizo posible el desarrollo de las complejas sociedades humanas en las que hoy se habita.

A partir de estas premisas, los grupos humanos evolucionaron en subgrupos y crearon normas, instituciones y culturas, unidos a los medios de control y autorregulación por medio de la moral y a las sanciones colectivas (Tomasello \& Amrisha, 2011). En la actualidad los humanos, como seres culturales, se integran y se identifican con las convenciones, normas e instituciones establecidas en un grupo específico.

En el presente análisis se realiza una aproximación a la teoría de la evolución socio-cognitiva y su relación con la creación de las normas, instituciones, la cultura, la moral y los roles. A partir del surgimiento de la cultura se explica la creación de roles y la moral en las diferentes culturas. La moral juzga el comportamiento de los miembros del grupo: la reputación, la culpa y la vergüenza son algunas de las sanciones que surgen en los orígenes y que prevalecen como una valoración social e individual. 
A través de la creación de los roles y los estereotipos sociales surge paralelamente un tipo de violencia simbólica, cuando estos son usados para controlar, autorregular y coaccionar la conducta de las mujeres en los estereotipos femeninos.

En la psicología del desarrollo moral se plantean tres teorías en relación con el desarrollo de la moral: la teoría de la interiorización de las normas sociales, la teoría del aprendizaje social y la teoría cognitivo-evolutiva. La primera afirma que el desarrollo moral se produce por la socialización, el aprendizaje o la internalización de las normas y de la cultura. En esta perspectiva los procesos de razonamiento y la conformidad con las normas sociales no se encuentran determinados por una secuencia evolutiva, sino por la interiorización de las normas y la identificación con los padres (Teoría Psicoanalítica, Freud, 1905/1930). La segunda toma como referencia las dimensiones conductuales con énfasis en la acción del ambiente y el desarrollo de las habilidades de autocontrol (imitación, procesos de aprendizaje, refuerzos, castigos y prácticas educativas, Skinner, 1932). La tercera teoría (Kohlberg, 1976) afirma que el sujeto realiza la moral como una construcción por medio de la interacción con el medio, a través del desarrollo de reglas y la adquisición de principios universales. Los dos factores básicos del desarrollo moral lo constituyen la participación social y la asunción de roles (interacciones con los grupos sociales, posibilidad de asumir el rol de otros) y el desarrollo cognoscitivo (niveles y estadios). Bandura (1986; 1999) afirma que los seres humanos no nacen con conductas innatas, sino que son aprendidas a partir de la relación de los factores fisiológicos y las influencias de la experiencia.

El fenómeno de la subjetividad y la modernidad, de acuerdo con Habermas (1991), consiste en un estadio de aprendizaje reflexivo de las tradiciones y 
de la propia identidad. El autor señala que la moral del "individualismo" encuentra el fundamento normativo en la razón, deja de ser individual y social, para convertirse en intersubjetiva a través de la comunicación en la que socializan los individuos.

El desarrollo cognitivo y la creación de normas (Tomasello, 2014) en la evolución del pensamiento humano tiene dos momentos claves previos a la agricultura, la formación de ciudades, la organización social, las leyes y la religión. Es precisamente con la colaboración y posteriormente con la creación de grupos, que competían entre sí, como se fomentó la cooperación y la interacción humana, que posteriormente desarrollaron las convenciones culturales (Tomasello \& Amrisha, 2011).

Desde los orígenes de la ontogenia de la moralidad humana Tomasello (2011) existe en los seres humanos una predisposición al egoísmo Hobbes- y a la cooperación -Rosseau-, las cuales de forma conjunta contribuyeron con el desarrollo y evolución del pensamiento humano. El autor considera fundamental conocer cómo los seres humanos se convierten en seres morales preocupados por el bienestar del grupo sin desatender las necesidades individuales. Para mantener el bienestar de la colectividad los miembros deben supervisar a los otros y a sí mismos. Este es el inicio del agente-neutral a nivel grupal, basado en las normas de la cooperación y la moral humana (Tomasello \& Amrisha, 2011).

La necesidad de colaborar y cooperar para lograr objetivos comunes, en un contexto de interdependencia para la supervivencia, hace que los individuos del grupo se adapten a nuevas formas de convivencia (Tomasello, 2014). La transmisión generacional permite que el aprendizaje

Las normas, las instituciones y la cultura y la acumulación cultural sean posibles. Al traducir los elementos anteriores en normas e instituciones, mediante un acuerdo colectivo, no 
solo se determinó el surgimiento de los objetivos conjuntos, sino también el de los roles sociales e individuales, lis cuales incluían a las personas y a los objetos (Tomasello \& Amrisha, 2011).

Los seres humanos, para vivir de forma armoniosa en sociedad, deben convertirse en agentes intencionales, que manifiesten una preocupación por el bienestar grupal e individual. Al lograr una colaboración exitosa con los demás miembros se comprometen a aplicar, vigilar e imponer la observancia de las normas morales, aceptadas inicialmente, por medio de un agente-neutral impersonal (Tomasello \& Amrisha, 2011). La preocupación colectiva por las normas sociales y su efectividad descansa sobre las convenciones, las normas morales y el compromiso adquirido por los miembros de la colectividad. Las interacciones sociales de los primeros humanos posiblemente fueron únicamente personales-secundarias, y paulatinamente alcanzaron un mayor nivel de compromiso hasta llegar a las interacciones sociales de los humanos modernos y la preocupación por el bienestar colectivo.

La sociedad humana contemporánea (Tomasello, 2014) se caracteriza por dos dimensiones: la organización social sincrónica (coordina las interacciones que constituyen la sociedad) y la transmisión diacrónica de habilidades y conocimientos a través de las generaciones (evolución cultural acumulativa). De acuerdo con Tomasello y Amrisha (2011) los individuos aceptan estas normas sociales porque resultan prudentes y porque la transgresión conduce a una sanción moral, como la desaprobación, la murmuración y el ostracismo

"Norms go beyond the particular-they are general and agentneutral- in at least three ways. First, social norms articulate an objective standard of behavior that is mutually known by all in the 
group... Second, the force of the norm is not individual opinion but rather group opinion (or perhaps some other larger entity such as the group's gods), based ultimately in an agreement or commitment into which each individual enters...Third, the norm applies to everyone in the group (or perhaps the subgroup) equally, including the self". [Las normas generales van más allá de lo particular -son generales y el agente-neutral- en al menos tres formas. En primer lugar, las normas sociales articulan una conducta objetiva estándar la norma es conocida de forma mutua por todos en el grupo ... En segundo lugar, la fuerza de la norma no es una opinión individual, sino más bien la opinión del grupo (o tal vez alguna otra entidad más grande, como los dioses del grupo), basada en última instancia en un acuerdo o un compromiso en el que cada individuo entra ... en tercer lugar, la norma se aplica a todos los miembros del grupo (o quizás el subgrupo) por igual, incluyendo al individuo] (Tomasello \& Amrisha, 2011, p. 245).

En los seres humanos, las manifestaciones de la identidad y la conciencia de sí mismos se realizan en concordancia con la adaptación de la vida en sociedad. La existencia de metas, intenciones, conocimientos y creencias compartidas tienen un alto grado de motivación para lograr la integración en un grupo determinado, así se convierten en un factor fundamental para la evolución y el desarrollo de la comunicación humana y el lenguaje (Tomasello, 2014).

Los seres humanos modernos convencionalizan de forma colectiva la comunicación lingüística, a través de conceptualizaciones heredadas culturalmente y con un carácter arbitrario. Los comunicadores humanos conceptualizan situaciones y entidades por medio del proceso dialógico con los otros. El discurso, como parte de la comunicación lingüística, 
permite expresar con mayor precisión el pensamiento humano. La cooperación, en función de las normas y convenciones culturales del grupo, determina su existencia, por esta razón:

"In many ways, the most distinctive feature of human social organization is its normative structure. Human beings not only have statistical expectations about what others will do-which all apes havethey also have normative expectations about what other should do. These vary across different cultures and form a continuum from moral norms (typically concerning harm to others) to social conventions". [En muchos sentidos, la característica más distintiva de la organización social humana es su estructura normativa. Los seres humanos no sólo tienen expectativas estadísticas acerca de lo que otros harán -todos los primates lo hacen- también tienen expectativas normativas acerca de lo que el otro debe hacer. Estas varían en las diferentes culturas y forman un continuo que va desde las normas morales (por lo general en relación con el daño a otros) a las convenciones sociales] (Tomasello \& Amrisha, 2011, p. 238).

La cultura por medio del lenguaje, los procesos de socialización, el aprendizaje, las relaciones, las normas y los valores, permiten a los seres humanos interactuar socialmente mediante la aceptación de un compromiso establecido con la normatividad impuesta por la colectividad. Al adoptar la cultura de un grupo, los sujetos se insertan en una jerarquía y aceptan un conjunto de normas sociales implícitas en el compromiso adquirido para respetar las expectativas del grupo (Tomasello \& Amrisha, 2011). 
La institucionalidad de la realidad es la forma en que se hace público el modelo y las normas simbólicas de las instituciones culturales. La enseñanza es crucial en el proceso, ya que las convenciones culturales son aprendidas y no inventadas, se imitan, se transmiten y se acumulan a través del tiempo. Existe un compromiso por parte del individuo con la identidad social del grupo, la cual indica la forma correcta de hacer las cosas en el entorno.

Tomasello (2014) afirma que posiblemente los primeros humanos aceptaron de forma activa las normas de comportamiento que el grupo establecía e imponía a través de la enseñanza y la aplicación de las normas sociales generales. Una vez que los seres humanos formaron grupos para realizar objetivos de forma conjunta, evidenciaron un compromiso mayor con el fin de evitar causar daño o decepcionar a los otros, al no cumplir con las expectativas de la colectividad (Tomasello \& Amrisha, 2011).

La interdependencia del individuo hace que este acepte de forma inherente las normas y los roles impuestos culturalmente. La división de roles, diversos estatus y la división del trabajo ocasionan las diferencias y desaparecen parcialmente la equidad con los diversos patrones de conducta que surgen para cumplir con las necesidades y expectativas del grupo.

Durante los orígenes de la evolución del pensamiento humano (Tomasello, 2014), las normas sociales operaron de modo genérico (objetividad, fuente, meta) y los roles incluyeron los estándares de un agente neutral específico. Los individuos asumen roles, estatus, obligaciones y poder deóntico, de acuerdo con lo dictaminado por las instituciones de la sociedad. 
La creación de instituciones sociales contribuye con la existencia de la colaboración en los objetivos compartidos y los roles sociales individuales dentro del grupo. Los individuos asumen roles, estatus, obligaciones y poder deóntico, de acuerdo con lo dictaminado por las instituciones de la sociedad: Los seres humanos asignan un estatus y un valor especial a los roles sociales, los cuales son reconocidos por la colectividad y a partir de aquí se crean derechos y obligaciones (Tomasello \& Amrisha, 2011). De esta forma es posible establecer una serie de roles predeterminados para los individuos, cuyas funciones e incumplimiento suponen una sanción social que afecta moralmente al individuo.

La colectividad determina no solo el comportamiento "correcto" dentro de una cultura, sino que se encarga de asignar los roles y determinar la identidad social de los individuos. Las perspectivas incluyen así las valoraciones del grupo y son cruciales para la generalización y la objetividad de las normas sociales e institucionales: "In the case of morality, the institutions of law and organized religion obviously interact in important ways with humans' natural proclivities for cooperation and norm following to produce an institutional dimension to much of human morality”. [En el caso de la moral, las instituciones de la ley y de la religión organizada, obviamente, estas interactúan de manera relevante con las inclinaciones naturales de los humanos para la cooperación y el seguimiento de normas que producen una dimensión institucional en gran parte de la moralidad humana] (Tomasello \& Amrisha, 2011, p. 248).

La capacidad de autorreflexión para evaluar a otros y la autoevaluación que ocurre por medio de la conciencia autorreflexiva y la comunicación simbólica, forman parte de los procesos cognitivos que permiten la construcción social de una identidad que se asigna a los sujetos y que

\section{Los roles y los estereotipos}


determina los roles de comportamiento evaluados y juzgados por la colectividad.

Al respecto, Tomasello y Amrisha (2011) afirman que en la sociedad adulta las normas sociales, los acuerdos y los compromisos mutuos forman parte de las expectativas del comportamiento adecuado, en las diferentes situaciones de convivencia social. Las expectativas fundamentadas en el compromiso y la aceptación mutua fomentan en alguna medida la construcción de patrones de conducta en relación con los roles, al establecer y tipificarlos, estos se fijan a través de una categorización y clasificación de conductas y acciones que son reconocidas como estereotipos.

Las personas desarrollan ideas sobre las conductas apropiadas para ambos sexos, al generalizarlas desde la información de modelos ejemplares específicos y un comportamiento delineado acorde con los modelos establecidos. La conducta y los roles de género, en la teoría social cognitiva, tienen tres modelos de influencia principal para explicar la forma en que la información es cognitivamente procesada: la imitación a través de modelos, la influencia de la experiencia representativa y la influencia a través de instrucción directa (Bandura \& Bussey, 1999). Para estos autores el impacto de los elementos puede variar de acuerdo con el estatus del desarrollo de los individuos y la estructura social de las experiencias.

El comportamiento relacionado con las conductas del género usualmente es sancionado socialmente en las diversas culturas. La valoración social y las reacciones del grupo se convierten en fuentes de información para la construcción de las conceptualizaciones de género (Bandura \& Bussey, 1999). La división entre los sexos (Bordieu, 2000) es social y 
arbitrariamente construida, desde su estado objetivo presenta una normatividad y legitimidad del sistema de las estructuras cognitivas y sociales. Así, ligada a lo natural como inevitable para los cuerpos y los hábitos de sus agentes en los sistemas de esquemas de percepciones y estructuras en el mundo social. Gilligan y Attanucci (1988) afirman que las orientaciones morales se encuentran ligadas a las similitudes y diferencias de género. Los estereotipos, para la autora, señalan a las mujeres ligadas más a la crianza y a los hombres como seres más lógicos.

La diferenciación de los seres humanos, a través de los roles de género, hace posible la creación de estereotipos que surgen en las relaciones intergrupales. Los estereotipos forman parte de un grupo de características y creencias compartidas por los miembros de una sociedad determinada. De forma tal que los cambios del desarrollo de la teoría cognitiva social se refieren tanto a los atributos y las actividades que tienen género, como a los mecanismos de control de la conducta (Bandura, 1986;1991b, citado por Bandura \& Bussey, 1999, p. 706).

En la creación de los estereotipos, el individuo es juzgado y valorado, por los demás miembros del grupo al cual pertenece, en relación con sus acciones:

"In stereotyping, the individual: (1) categorizes other individual, usually on the basis of highly visible characteristics such as sex or race; (2) attributes a set of characteristics to all members of that category; and (3) attributes that set of characteristics to any individual member of that category”. [El concepto de género no es sinónimo de mujer sino que comprende los atributos y valores socioculturales asignados de acuerdo con las interrelaciones y funciones de cada sexo. En los estereotipos, el individuo: (1) 
categoriza otro individuo, por lo general sobre la base de características muy visibles, como el sexo o la raza; (2) los atributos de un conjunto de características a todos los miembros de esa categoría; y (3) los atributos de ese conjunto de características a cualquier miembro de esa categoría] (Snyder, 1981, p. 415; citado por Banaji, M \& Greenwlad A. 1995, p.15; citados por Bandura \& Bussey, 1999).

Diversas teorías se han desarrollado a lo largo del tiempo para explicar el desarrollo del género1: la teoría psicoanalítica, la teoría del desarrollo cognitivo, las teorías biológicas, las teorías sociológicas y la teoría social cognitiva se encuentran entre las principales. La teoría social cognitiva reconoce la importancia del rol evolutivo como factor de la adaptación y el cambio en los seres humanos (Bandura \& Bussey, 1999). El desarrollo del género es explicado de acuerdo con una causalidad tríadica recíproca: primero, la presencia de los factores personales (eventos cognitivos, afectivos y biológicos que influyen en las concepciones ligadas con el género); segundo, los patrones de conducta (estándares evaluativos y valorativos de comportamiento autorregulativo); y tercero, los eventos ambientales (influencias sociales en la vida cotidiana) (Bandura \& Bussey, 1999).

El "sexo" entendido como la base material o natural para determinar la imposición de género, como un concepto sociológico o cultural, se encuentra determinado por un sistema social donde la categoría mujer y hombre se encuentra asociada al "sexo biológico" considerado como natural dentro de la lógica binaria del género. De esta forma lo "aparentemente biológico" y los efectos reales que se constatan en los cuerpos y las mentes son el resultado de un largo periodo de socialización colectiva. 
Una consecuencia de este proceso es la forma en que se conjugan las causas y los efectos para presentar una construcción social naturalizada (Bordieu, 2000). Esta última aparece como natural, para el autor, y por lo tanto señala que la división del género es arbitraria en el principio de la representación de la realidad. Por esta razón, se enfatiza la forma como la sociedad y la percepción del individuo se encuentra entrelazada con las percepciones de la colectividad, la cual impone las normas a los miembros de un grupo específico:

La experiencia práctica del cuerpo, que se engendra al aplicar al propio cuerpo los esquemas fundamentales derivados de la asimilación de las estructuras sociales y que se ve continuamente reforzado por las reacciones engendradas de acuerdo con los mismos esquemas, que el propio cuerpo suscita en los demás, es uno de los principios de la construcción en cada agente de una relación duradera con su cuerpo (Bordieu, 2000, p. 85).

En la teoría social cognitiva (Bandura, 1986, citado por Bandura \& Bussey, 1999) la función de los miembros del grupo y la interdependencia resultan fundamentales en el establecimiento de las categorías de género. De acuerdo con los autores, los subgrupos y su dinámica son los que establecen las sanciones sociales, las cuales son interdependientes de dichos sistemas y permanecen más allá de la formación inicial del grupo al mantener una diferenciación de género.

Las relaciones de género varían a través de tiempo y las diferentes épocas de la historia. La dominación masculina y la sumisión de las mujeres se muestran como procesos complejos e inestables, influenciados por las acciones de los sujetos sociales. Desde esta perspectiva, los estereotipos de género son funcionales y operativos en la sociedad al crear identidades de 
género, las cuales son fijadas a través de los estereotipos que establecen conjuntos de valores y creencias, a partir de lo prescrito socialmente para ser hombres y mujeres en un espacio temporal, social e histórico determinado. En este aspecto resulta importante señalar que:

"In the gender domain, most gender-linked outcomes are socially prescribed rather than intrinsic to action. They include socially based consequences such as approval, praise and reward form activities traditionally linked to the same gender, and disapproval or even punishment for those linked to the other gender". [En el campo del género, la mayoría de los resultados vinculados con el género están socialmente prescritos en vez de estar ligados a la acción intrínseca. Estos incluyen consecuencias de base social, tales como la aprobación, la alabanza y la recompensa, en las actividades tradicionales vinculadas al género, y por otra parte con la desaprobación o el castigo para las acciones vinculados con el otro género]. (Bandura \& Bussey, 1999, p. 696).

Las identidades de género son diversas y no necesariamente corresponden al sexo con el que una persona nace. Existe, por lo tanto, una feminidad y una masculinidad hegemónicas que se imponen como modelos dominantes; pero existe una variedad de formas de construir y experimentar el género en un cuerpo que puede ser de hombre o de mujer. La identidad es lo que permite a cada grupo, comunidad o persona distinguirse de los demás, así como asimilarse y tomar distancia entre el yo, el nosotros(as) y los otros(as); se construye a través de procesos subjetivos que se interiorizan y que poseen un significado para la persona que forma parte de un grupo, pero también exhibe un componente objetivo que resulta de una identificación atribuida por los otros. 
La percepción de la identidad femenina aceptada culturalmente señala como negativos ciertos comportamientos sociales que se asocian con las identidades de género relacionadas con el cuerpo, mas su vínculo es simbólico en la medida que se expresan a través de las imágenes mentales, como las representaciones culturales que forman parte del universo simbólico y de la ideología dominante existentes en una sociedad.

Las normas legitiman y mantienen el orden en la sociedad, pero también pueden convertirse en un orden de opresión y desigualdad para los miembros que la conforman. La moral impuesta a los integrantes de un grupo determinado se fundamenta en la evaluación y valoración social como mecanismo que controla a los individuos dentro del grupo social. La cultura, a través de las instituciones y las normas, establece un sistema de control de los miembros en el cual se enseñan y se aprenden una serie de conductas y roles cuya existencia contribuye a la estabilidad de la sociedad.

El acuerdo y el compromiso tácito que el individuo adquiere cuando nace en una sociedad específica se encuentra regulado e impuesto por la cultura, la moral, la costumbre y la distribución de roles. Lo anterior lleva a una división de roles individuales y grupales establecidos para el bienestar de la colectividad.

La observancia y control se ejerce por medio de sanciones establecidas con el fin de evitar las transgresiones. Las sanciones incluyen diversas formas dentro de las cuales se encuentra no solo la sanción social, sino también el autocastigo frente al incumplimiento de las normas (Beauvoir, 2000; Gilbert y Gubar, 2000; Macaya, 1997,1992; Sagot, 1995; Osborne, 2001) y la valoración negativa del individuo y la colectividad a través de la vergüenza, la culpa, la reputación (Tomasello \& Amrisha, 2011; Tomasello, 2014). 
Los procesos de socialización forman parte integral de la vida de las personas, se crece en una sociedad aceptando normas y modelos establecidos por el sistema, en agentes socializadores no solo cuando cumplimos con lo establecido, sino cuando nos aseguramos de que las normas sean aplicadas y cumplidas. La política se relaciona con el poder social y la dominación a través de las sanciones, las transgresiones de las normas e instituciones establecidas deben ser impuestas por la sociedad; "Third-party punishment may be thought of as a kind of cooperative enforcement of peace and well-being in the group and plays a critical role in the creation and maintenance of social norms in general". [El castigo de terceros puede ser considerado como una especie de aplicación de la cooperación para mantener la paz y el bienestar en el grupo y juega un papel fundamental en la creación y el mantenimiento de las normas sociales en general] (Tomasello \& Amrisha, 2011, p. 238).

La transgresión a las normas establecidas afecta al individuo más allá del espacio individual, porque contraviene el pacto y el compromiso realizado con el grupo. Por esta razón, la sanción a través de un tercer agente es fundamental para la cohesión y estabilidad del grupo:

"Guilt, shame, and pride are thus internalized versions of the kind of moral judgments that humans meet out to others who violate or follow social norms. These norm-related, self-conscious emotions thus demonstrate with special clarity that the judgment being made is not my personal feeling about things, but rather the group's. I am sanctioning myself or praising myself on behalf of the group, as it were”. [La culpa, la vergüenza y el orgullo son así internalizados versiones como un tipo de juicios morales que los seres humanos imponen a los que violan o cumplen las normas sociales. Por tanto, estas normas relacionadas con emociones autoconscientes 
demuestran con claridad que el juicio que se emite no es la opinión personal individual sobre las cosas, sino la opinión del grupo. Al sancionarme o alabarme a mí mismo, lo hago en nombre del grupo] (Tomasello \& Amrisha, 2011, p. 248).

Las masculinidades y feminidades implican algo más que los comportamientos psicológicos o los papeles sociales que representamos en la vida cotidiana, también suponen discursos, supuestos, normatividades y valores. Los diferentes órdenes socioculturales convergen en los patrones de representaciones simbólicas que imponen, producen o garantizan la socialización de un "deber ser/hacer sociocultural" según el género (Aguilar, 2002).

En este sentido, es posible comprender que, si bien la identidad puede elegirse, la sociedad también impone una identidad en relación con la normatividad establecida. Si bien es cierto el tener una concepción de género asumida no obliga a representar el estereotipo socialmente aceptado, igualmente la autoconciencia del género no crea necesariamente una valoración positiva de los atributos tradicionalmente asignados. Tanto la valoración, como ciertos atributos y roles y la necesidad de adaptarlos, se encuentran influenciados por una valoración asignada por la colectividad (Bandura \& Bussey, 1999).

La forma de comportarse en sociedad, de acuerdo con (Buttler, 1999) presenta al género como performatividad, es decir, una actuación reiterada y obligatoria en función de unas normas sociales. No constituye un hecho aislado del contexto social, sino una "performance" signada siempre por un sistema de premios y castigos. La regulación de la conducta y los roles de género se regulan por medio de sanciones sociales ligadas al 
comportamiento asignado a hombres y mujeres, cuando su conducta atenta contra las diferencias jerárquicas en la esfera del orden social.

La interiorización de estas pautas de sumisión se fundamenta en creencias sociales sobre las cuales se mantienen las relaciones de poder y la sumisión en las relaciones afectivas. Aguilar (2002) afirma que la violencia simbólica es acumulativa, mutable y reversible, lo cual incrementa y explica su eficacia reproductiva, de siglos a siglos, de unos períodos históricos a otros. De acuerdo con la autora, lo anterior ocasiona que lo impuesto y arbitrario se convierta en legítimo y oficial, permitiendo que las relaciones de poder y la sumisión se perpetúen como relaciones de interacción asimétrica entre hombres y mujeres.

Los estudios de género, en la actualidad, han diversificado su área de acción a diferentes ámbitos del discurso cultural. La violencia de género se posiciona en las teorías que investigan el proceso de deslegitimación de la violencia contra las mujeres y la elaboración de un nuevo marco de interpretación. El feminismo, como teoría y como movimiento social, ha tenido un azaroso camino para redefinir la violencia contra las mujeres como un problema social y político.

Existen diferentes taxonomías del concepto violencia, Pinker (2012) la categoriza adaptando el esquema de Baumeister (1997). Así, señala como raíces de la violencia la práctica instrumental, explotadora o depredadora. Para el autor esta violencia es la más sencilla, pues se usa la fuerza para conseguir el fin (codicia, lujuria, ambición, otros). Una segunda raíz es la dominación (la búsqueda de supremacía sobre los otros), una tercera es la venganza (furia y miedo), la cuarta es el sadismo (placer de causar daño) y la quinta es la de la ideología (tejen motivos credo y se recluta a otros para que realicen sus fines destructivos (Pinker, 2012).

\section{La violencia y los estereotipos femeninos}


La violencia también puede definirse como "Todo acto verbal, físico, sexual, directo o indirecto que lesione a otra persona física o emocionalmente y que tenga por objeto mantener una relación de poder o simplemente ejercerlo" (Vega et al., 1994, citados por Aguilar, 2002, p. 17). La violencia ejercida contra las mujeres por el hecho de ser tales se conoce teóricamente como violencia de género. ${ }^{2}$ El concepto género hace referencia a una forma primaria de relaciones significantes de poder, la cual impone y condiciona simbólicamente, patrones, valores, conductas, percepciones y esquemas "deber ser/hacer sociocultural".

El efecto de la dominación simbólica en relación con el sexo, la cultura, la lengua, la etnia y otros, se produce a través de los diferentes esquemas de percepción, de apreciación y de acción. La violencia simbólica, considerada como implícita o invisible, se caracteriza porque transforma en naturales aquellas modalidades culturales que tienen por finalidad someter un determinado grupo social, utilizando estrategias que han sido desarrolladas por aquellos que tienen el poder (Bordieu, 2000). En el discurso oficial, el lenguaje incorpora los sentidos y referentes sociales, los mandatos y el orden que impone una conducta que determina lo que se debe hacer, ser y decir para formar parte de la colectividad.

La violencia de género tiene sus raíces en el sistema patriarcal que jerarquiza las acciones y espacios en función de un varón que somete a la mujer. El varón mantiene el poder sobre el resto de los hombres de la sociedad patriarcal, investido con los derechos y privilegios institucionalizados en los contextos sociales, culturales y legales. La legitimación del sistema que autoriza la masculinidad hegemónica y el dominio masculino sobre las mujeres, existe en diversas culturas, las cuales asumen a las mujeres como inferiores y como propiedad de los varones. 
La Declaración de las Naciones Unidas sobre la eliminación de la violencia contra la mujer, de 20 de diciembre de 1993 (Resolución 48/104), reconoce que esta:

constituye una manifestación de relaciones de poder históricamente desiguales entre el hombre y la mujer que han conducido a la dominación de la mujer y a la discriminación en su contra por parte del hombre e impedido el adelanto pleno de la mujer, y que la violencia contra la mujer es uno de los mecanismos sociales fundamentales por los que se fuerza a la mujer a una situación de subordinación respecto del hombre. ${ }^{3}$

El dominio se encuentra relacionado con el deseo de autoridad, prestigio, gloria y poder en la lucha por la supremacía que surge entre los grupos étnicos, religiosos, entre otros (Pinker, 2012). Así, la dominación masculina sobre las mujeres es parte del sistema y la ideología patriarcal. El componente de la estructura se refleja en la organización jerárquica de las instituciones y relaciones sociales, las cuales por medio de la ideología racionalizan la desigualdad de forma que contribuye a legitimar ese orden natural (Sagot, 1995, citada por Aguilar, 2002, p. 59).

La práctica de la violencia simbólica en el sistema patriarcal define a las mujeres y las predispone a la violencia explícita e implícita. El sistema de representaciones simbólicas en la cultura impuesto por el andrologocentrismo, somete, sanciona y discrimina a las mujeres. El sistema sociocultural construido es "jerárquico y patriarcal, sancionador de toda (o) aquel que no acepta ni ingresa en su estatuto significativo, por medio de actos discriminatorios aplicados por género" (Aguilar, 2002).

Desde una perspectiva multidisciplinar de interpretación, diversas autoras como Beauvoir (2000), Millet (1970), Lerner (1990), Osborne (2001), 
Buttler (1999), Lagarde, (1996), Bernárdez (2001), Gilbert y Eby (2004), entre otras, señalan que la violencia ejercida contra las mujeres se convierte en una forma de violencia estructural sobre el colectivo femenino. El mundo sexualmente jerarquizado hace que las mujeres acepten un silenciamiento e invisibilización que se traducen en la aceptación de un sistema de prohibiciones y prescripciones arbitraria donde:

El orden social funciona como una inmensa máquina simbólica que tiende a ratificar la dominación masculina en la que se apoya: es división sexual del trabajo, distribución estricta de las actividades asignadas a cada uno de los dos sexos, de su espacio, su momento, sus instrumentos (Bordieu, 2000, p. 22).

Al hablar de la violencia de género no se excluye a las diferentes identidades sexuales. La imagen social del cuerpo, con la que cada agente tiene que contar desde muy temprano, se obtiene, por tanto, mediante la aplicación de una taxonomía social, cuyo principio coincide con el de los cuerpos a los que se aplica (Bordieu, 2000).

El grupo de disposiciones y directrices que la sociedad patriarcal impone a las mujeres tienen un carácter simbólico y son reforzadas al ser legitimadas de forma no consciente, a través de las pautas de reproducción del orden social patriarcal, por medio de la normativa institucionalizada de la cultura dominante; por lo que "las personas no solo enseñan y valoran los estándares prescritos para los demás, sino que ejemplifican con su conducta las reacciones que esta les produce (Bandura \& Bussey, 1999).

La importancia de comprender la vigencia del fenómeno de la violencia contra las mujeres exige volver la mirada hacia los textos literarios para conocer cómo la cultura ha legitimado la violencia de género durante 
siglos. La violencia ejercida a través de lo simbólico sirve para degradar, intimidar, manipular y desvalorizar el respeto y la identidad personal de los individuos.

La diferenciación de los seres humanos, por medio de los roles de género, posibilita la creación de los estereotipos que surgen en las relaciones intergrupales. Los estereotipos forman parte de un grupo de características y creencias compartidas por los miembros de una sociedad específica. Desde una perspectiva de Estudios de la Mujer, el género se constituye en una categoría cambiante que asigna una clasificación cultural particular a los individuos, determinada por las diferencias de poder y jerarquía (Millet, 1970; Gilbert \& Eby, 2004) en los roles sociales.

El género como categoría de análisis permite reflexionar sobre algunas de las implicaciones sobre la feminidad y su importancia en la vida de los seres humanos. La organización social, basada a lo largo de la historia en la estratificación sexual, reconoció dos cuerpos diferenciados: el femenino y el masculino. Esta distinción estableció modelos de conducta para ambos, desde los sistemas de representación implícitos en los roles, modelos, imágenes, mitos y estereotipos.

Percibir la violencia en las actividades diarias es difícil, pues se inserta en las organizaciones sociales y en las dinámicas relacionales. Usualmente se asume la violencia como un acto físico que involucra a quien la sufre; no obstante, es importante resaltar que los signos de violencia aparecen invisibilizados en la sociedad y en las instituciones. Por lo tanto, se muestra como una "Violencia amortiguada, insensible para sus propias víctimas, que se ejerce esencialmente a través de los caminos puramente simbólicos de la comunicación y del conocimiento o, en último término, del

\section{Los estereotipos, la moral femenina y la violencia simbólica}


sentimiento" (Bordieu, 2000, p. 51). La violencia simbólica es velada, pues se muestra de forma que se asume como natural y se presenta bajo diferentes categorizaciones como la imposición, la legitimación, el orden, la minimización, la negación, la desvalorización, la autoridad, la deslegitimación, la dominación sexual, la inferiorización, la subordinación y la coerción.

El imaginario social, como portador del discurso patriarcal (ideología, valores, ética) ha determinado lo que es, y lo que no es, ser mujer en las diversas sociedades. De esta forma, se han definido las necesidades, roles, funciones e incluso los deseos. El lenguaje y la cultura tienen un papel fundamental, pues presentan como "verdades inmutables" las normas e instituciones de los grupos dominantes. El discurso de la oficialidad (política, religión, ciencia, historia) con frecuencia silencia los discursos marginales. Los modelos de conducta han sido establecidos a lo largo de la historia y la participación social y cultural en la toma de decisiones en el espacio público ha relegado a las mujeres hasta épocas recientes.

La culpa se construye socialmente y los seres humanos, a través de las normas, establecen su subjetividad en las relaciones y vínculos, así como en el grado de satisfacción en relación con su desempeño y el reconocimiento social de este. La construcción de la subjetividad femenina en el imaginario social es reforzada por instituciones como las leyes, religión, historia y ciencia, todos estos espacios desde los que se ha ofrecido una interpretación negativa y cargada de prejuicios, a partir de la diferencia sexual, que garantizan su continuidad (Huertas, 2010). Las diferentes épocas y culturas han transmitido de forma implícita y explícita, por medio de patrones familiares, educativos y sociales, el reforzamiento de los roles y los estereotipos femeninos, a través de argumentos legales y simbólicos que introducen la sanción moral a través de la culpa. 
La culpa y la vergüenza surgen como consecuencia de haber transgredido una norma: no se ha hecho lo que se debía hacer en un caso determinado. Usualmente, la culpa puede destruir a quien la asume, si se asume más allá de la responsabilidad que corresponde. El clasificar una conducta como culpable, vergonzosa, o como pérdida del honor y la reputación, constituye un juicio de valor moral dentro de un grupo social y su imposición como castigo de reprobación constituye una amenaza a la integridad psíquica de las personas.

En el orden sociocultural, las representaciones simbólicas incluyen paradigmas, creaciones, comportamientos, lenguajes y fantasías, las cuales tienen valor de imposición a partir de normas que se imponen desde el sistema simbólico como instrumento de dominación (Bordieu, 2000).

El individuo, etimológicamente del latín individuum, significa lo indivisible, la unidad indivisa e indivisible. De individuo deriva el término individuación, el cual define todo aquello por lo que el individuo es uno, aquello que lo diferencia de los demás. En la psicología social, la diferencia del individuo en su relación con los demás no significa ausencia de relación, sino más bien señala la apertura o la capacidad de comunicación con los otros. El sujeto, cuya raíz etimológica en el latín remite a subiectum, significa lo puesto debajo, lo que se encuentra en la base. En la ontología es "la realidad que está en la base", "lo que sostiene", "lo que sustenta"; indica entonces una relación con otra que descansa sobre él. El sujeto del modernismo se convierte en portador de actos, con una autocognición intencional. El sujeto asume un primer plano en la edad moderna, ocupa el lugar preeminente en relación con el objeto al que apunta con el acto intencional.

El individuo, como actor social, vive y reproduce un contexto social basado en las interacciones cotidianas de su entorno. El mundo social en el que se 
desenvuelve forma parte de la intersubjetividad, es decir, es el mundo donde se inserta y se reconoce, pero reconoce al otro con el que se interrelaciona. A partir de este reconocimiento, el sujeto tiene la habilidad de no solo reconocer al otro, sino de ponerse en su lugar; se trata de ese reconocimiento análogo al "yo" que plantea Mead (Habermas, 1990). El espacio de la intersubjetividad permite percibir no solo sus actos, sino también los actos de los otros en el espacio y el tiempo. La existencia de un "yo" y un "otro", que forma un "nosotros", obliga a reconocer mutuamente el mundo de relaciones del cual se forma parte y en el cual surge la interrelación.

La comunicación es el medio por el cual se concreta la realidad social, es el espacio donde se otorga y se comparte sentidos a nivel de objetos (referencial), de relaciones entre los hablantes (interreferencial) y donde se realiza la construcción del sujeto como individuo social (autorreferencial). A través de la comunicación en los diferentes niveles y el discurso oficial (poder), se establecen las relaciones y la interacción. La percepción que se logra a partir de esta interacción forma parte de la intersubjetividad como proceso que integra al individuo con los miembros y la sociedad a la cual pertenece.

El estudio de la literatura como espacio-temporal idóneo para la investigación de los estereotipos femeninos permite conocer los mecanismos mediante los cuales se crean y se reproducen los roles y estereotipos en los textos (Beauvoir, 2000; Ellman, 1968; Belsey, 1980; Macaya, 1992; Gilbert \& Gubar, 2000). Lo anterior a partir de la relectura y reinterpretación de las construcciones socioculturales de los personajes femeninos. Las mujeres, como personajes literarios, permiten una aproximación desde los textos para analizar los significados primarios que 
se atribuyen a cada sexo en el código simbólico establecido por la tradición cultural.

La decodificación incluye referentes concretos de la sociedad y las ideologías y las identidades que interaccionan en el contexto.

La desigualdad en el orden sociocultural (económico, legal, religioso, familiar, político y otros), entre hombres y mujeres, perpetúa la violencia en todos sus aspectos. La violencia de género es un tema complejo, cuya interpretación y análisis se encuentra ligado a diferentes aspectos de significación personal y cultural. De ahí la necesidad de la interdisciplinariedad para determinar las creencias y tradiciones sobre los roles asignados a las mujeres como forma de dominio masculino.

Si bien el análisis de la violencia contra las mujeres es un fenómeno reciente, los antecedentes se remontan a la antigüedad, de ahí la necesidad de no aislar el estudio de esta categoría, sino investigar su nacimiento y existencia en la literatura, como medio para reproducir la ideología en los textos. 
Aguilar, V. (2002). La violencia simbólica entretejida en la enseñanza del Derecho Penal. Tesis de Maestría. San José: Universidad de Costa Rica.

Bandura, A., \& Bussey, K. (1999). Social Cognitive Theory of Gender Development and Differentiations. Pyschological Review, 106, pp. 676-713.

Baumeister, R. (1997). Evil: inside human violence and cruelty. New York: Holt.

Beauvoir, D. S. (2000). El segundo sexo.

Belsey, K. (1980). Critical Practice. New Jersey: Routledge.

Bernárdez, A. (2001). Violencia de género: sociedad: una cuestión de poder. Madrid: Instituto de Investigaciones Feministas.

Bordieu, P. (2000). La dominación masculina. Barcelona: Anagrama.

Buttler, J. (1999). Gender Trouble. New York: Routledge.

Díaz, T., \& Rocha, R. (2005). Cultura de género: La brecha ideológica entre hombres y mujeres. Anales de Psicología, 21 (1), pp. 42-49.

Ellman, M. (1968). Thinking about women. New York: Harcourt.

Gilber, S., \& Gubar, S. (2000). La loca del ático. Barcelona.

Gilbert, P., \& Eby, K. (2004). Violence and Gender. (P. Gilbert, y K. Eby, Eds.) New Jersey: Pearson Prentice Hall.

Gilligan, C., \& Attanucci, J. (1988). Two moral orientations: Gender differences and similarities. Merrill-Palmer Quarterly, 34, pp. 223237.

Greenwald, A., \& Banaji, M. (1995). Implicit Social Cognition: Attitudes, Self-Eteem, and Stereotypes. Pyschological Review, 102 (1), pp. 427. 
Habermas, J. (1990). Individuación por vía de socialización. Sobre la teoría de la subjetividad de George Herbert Mead. In J. Habermas, Pensamiento postmetafísico (pp. 188-239). Madrid: Taurus Humanidades.

Habermas, J. (1991). Sobre la relación entre política y moral. Buenos Aires: Almagesto.

Huertas, M. (2010). La culpa de las mujeres como instrumento de violencia y de mantenimiento de la estructura patriarcal. Miedos, culpas, violencias invisibles y su impacto en la vida de las mujeres: iA Vueltas con el Amor! Fundación Isonomía.

Kohlberg, L. (1976). Moral stages and moralization: The cognitivedevelopmental approach. In T. Lickona (Ed.), Moral Developmente and Behavior: Theory, Research and Social Issues. New York: Rinehart.

Lagarde, M. (1996). Género y feminismo. Desarrollo humano y democracia. Madrid: Horas y horas.

Lerner, G. (1990). La creación del Patriarcado. Barcelona: Crítica.

Macaya, E. (1992). Cuando estalla el silencio. San José: Universidad de Costa Rica.

Macaya, E. (1997). Espíritu en carne altiva. San José: Universidad de Costa Rica.

Millet, K. (1970). Sexual Politics. New York: Doubleday.

Organización de las Naciones Unidas (ONU). (1994). Declaración sobre la eliminación de la violencia contra la mujer (Resolución 48/104 del 20 de diciembre de 1993). New York: Naciones Unidas. Recuperado de http://www.un.org/es/comun/docs/?symbol=A/RES/48/104

Organización de las Naciones Unidas (ONU). (1995). Declaración de Beijing de 1995, y Plataforma para la Acción. IV Conferencia Mundial sobre las Mujeres. Beijing, China, Madrid: Ministerio de Asuntos Sociales, Instituto de la Mujer. 
Osborne, R. (2001). La violencia contra las mujeres. Realidad social y politicas públicas. Madrid: UNED.

Pinker, S. (2012). Los ángeles que llevamos dentro. El declive de la violencia y sus implicaciones. Barcelona: Paidós.

Sagot, M. (1995). Violencia contra las mujeres: el continum de la muerte. Memoria. Seminario sobre sensibilización de género, leyes y políticas relacionadas con las mujeres. San José: Universidad de Costa Rica.

Tomas, C. (2010). La culpa como instrumento cultural de sumisión. In U. J. Fundación Isonoomía (Ed.), Miedos, culpas, violencias invisibles y su impacto en la vida de las mujeres. Actas del VI Congreso Estatal de Isonomía sobre igualdad entre mujeres y hombres.

Tomasello, M. (2014). A Natural History of Human Thinking. Massachusetts: Harvard University Press.

Tomasello, M. (2008). Origins of Human Communication. Massachusetts: MIT Press.

Tomasello, M., \& Amrisha, V. (2011). Origins of Human Cooperation and Morality. Annual Review of Psychology (64), pp. 232-55.

Vega, F. (1994). La víctima de los delitos sexuales en el proceso penal y el agresor en el sistema de penas. San José: Universidad de Costa Rica. 
1. El concepto de género no es sinónimo de mujer, sino que comprende los atributos y valores socioculturales asignados de acuerdo con las interrelaciones y funciones de cada sexo.

2. La Plataforma de Acción de la Declaración de Beijing (1996, p. 61) define "violencia contra la mujer" como todo acto de violencia basado en el género cuyo resultado posible o real es un daño físico, sexual o psicológico, incluidas las amenazas, la coerción o la privación arbitraria de la libertad, ya sea que ocurra en la vida pública o en la privada.

Convención Interamericana para Prevenir, Sancionar y Erradicar la Violencia contra la Mujer “(...) debe entenderse por violencia contra la mujer cualquier acción o conducta basada en su género, que cause muerte, daño, o sufrimiento físico, sexual o psicológico a la mujer, tanto en el ámbito público como en el privado" (Artículo 1) (ONU, 1995).

3. Organización de las Naciones Unidas (ONU). (1994). Declaración sobre la eliminación de la violencia contra la mujer (Resolución 48/104 del 20 de diciembre de 1993). New York: Naciones Unidas. Recuperado de http://www.un.org/es/comun/docs/?symbol=A/RES/48/104

Recibido: 05-octubre-2015 Aceptado: 20-febrero-2016

Todos los derechos reservados. Universidad de Costa Rica. Esta revista se encuentra licenciada con Creative Commons Reconocimiento-NoComercialSinObraDerivada 3.0 Costa Rica. (CC BY-NC-SA 3.0 CR)

Correo electrónico: humanidades@ucr.ac.cr Sitio web: http://revistas.ucr.ac.cr/index.php/humanidades 